\title{
A Comparative Study between Sub Mucous Diathermy with or without Inferior Partial Turbinectomy
}

\author{
Essam Ali Abo El-Magd ${ }^{*}$, Ibrahim Rezk², Karema Mohamed Sobh ${ }^{3}$ \\ ${ }^{1}$ Department of Otorhinolaryngology, Aswan Faculty of Medicine, Aswan University, Aswan, Egypt \\ ${ }^{2}$ Department of Otorhinolaryngology, Sohag Faculty of Medicine, Sohage University, Sohage, Egypt \\ ${ }^{3}$ Department of Public Health Medicine, Asuit Faculty of Medicine, Asuit University, Asuit, Egypt \\ Email: Karema55@yahoo.com, *esamali801@yahoo.com
}

How to cite this paper: El-Magd, E.A.A., Rezk, I. and Sobh, K.M. (2018) A Comparative Study between Sub Mucous Diathermy with or without Inferior Partial Turbinectomy. International Journal of Otolaryngology and Head \& Neck Surgery, 7, 26-33.

https://doi.org/10.4236/ijohns.2018.71004

Received: December 22, 2017

Accepted: January 28, 2018

Published: January 31, 2018

Copyright $(9) 2018$ by authors and Scientific Research Publishing Inc. This work is licensed under the Creative Commons Attribution International License (CC BY 4.0).

http://creativecommons.org/licenses/by/4.0/

\begin{abstract}
Objective: In this study we aimed to compare the effects of submucosal cauterization of the inferior turbinate with or without inferior partial turbinectomy. Materials and methods: In this prospective cohort study, 60 patients with inferior turbinate hypertrophy were randomized and divided into two groups. The first one was submitted to submucosal cauterization associated with partial turbinectomy, and the second one only submucous cauterization. Five items were assessed to compare both methods: pain, nasal bleeding, scarring, crustation and nasal air way patency. Follow-up was performed on days $1,14,30$ and 3 months later. Results: In both groups crusting formation was similar. Reactionary hemorrhage was more common in turbinectomy group. Scarring showed better results in the turbinectomy group in the first month postoperative, airway patency showed good results in $80 \%$ of the patients with turbinectomy. Conclusion: Submucosal cauterization with inferior partial turbinectomy has yielded better nasal patency when compared to submucosal electrocautery ablation alone.
\end{abstract}

\section{Keywords}

Inferior Turbinate Hypertrophy, Partial Inferior Turbinectomy, Submucosal Diathermy

\section{Introduction}

Chronic nasal airway obstruction is one of the most frequent symptoms encountered by the otorhinolaryngologist. The majority of these patients suffer from hypertrophied inferior turbinates [1]. Inferior turbinate hypertrophy is a 
common entity which sometimes does not respond to medical treatment and requires surgery [2]. Different surgical techniques include turbinectomy, laser cautery, silver nitrate cautery, electrocautery, submucosal resection with or without lateral displacement, cryotherapy partial inferior turbinectomy (PIT) and submucosal diathermy (SMD) are two popular methods among the various techniques of inferior turbinate reduction [3]. The goal of all these different techniques is the maintaining of a normal physiology of the local mucosa. In order to achieve this, it is important to eliminate as much of the inferior turbinate bulk but keeping most of turbinate mucosa [4].

\section{Objective}

Comparative analysis of patients submitted to sub-mucosal electrocautery ablation with or without partial inferior turbinectomy.

\section{Materials and Methods}

We designed a prospective cohort study, recruiting 60 patients suffering from bilateral chronic nasal obstruction due to hypertrophied inferior turbinate. The study was conducted in the ENT department of Aswan university hospital, Aswan university. Egypt from January 2016 to January 2017 after approval from Aswan Ethical Committee and a formed consent taken from patients. Patients were divided into two groups of 30 people each. Group 1 patients underwent submucosal electrocautery ablation of the inferior turbinate coupled with partial turbinectomy, and group 2 underwent submucosal electrocautery ablation alone, without partial turbinectomy. All the patients underwent a medical interview and complete otolaryngology/head and neck physical exam. Both rigid and flexible endoscopes were used to assess the nasal cavities and the nasopharynx, CT nose and paranasal sinuses were done for every patient. Routine pre-operative investigations were done for every patient; both procedures were done under general anesthesia, with the patient in reclining position and head end of the table raised. Nasal cavity was packed with two cotton pled gets soaked in oxymetazoline and adrenalin. For SMD, after decongestion the diathermy needle was inserted into the anterior end of inferior turbinate, which was advanced submucosally till the posterior end of the inferior turbinate was reached. The needle was then withdrawn slightly and a current of 50 joules was applied in a triangular fashion at 3 points (superior, medial and inferior) For PIT, the inferior turbinate was infilterated with $2 \%$ xylocaine + adrenaline up to the posterior end. Using turbinectomy scissors, the medial one-third of the anterior end of the inferior turbinate was resected. All patients were given antibiotics for 7 - 10 days postoperative. The patients were assessed on the 1st, 14th, 30th day and 3 months postoperatively.

Post-operative follow-up we compared between the two groups according to the following parameter:

1) Reactionary hemorrhage. 
2) Improvement of nasal obstruction.

3) Degree of nasal pain.

4) Intranasal crustations.

5) Degree of tissue Healing.

Nasal obstruction was analyzed according to VAS (Visual Analogue Score) system by asking the patients to score relief of nasal obstruction post-operatively from 1 - 10 and was categorized as follow [5]:

- No improvement: VAS (1 - 3).

- Partial improvement: VAS (4 - 7).

- Complete improvement: VAS (8 - 10).

Intranasal pain was also analyzed according to VAS by asking the patients to score the post-operative pain from 1 - 10 and was categorized as follow [6].

- Mild pain: 1 - 3

- Moderate pain: 4 - 7

- Severe pain: 8 - 10

Extend of intra-nasal crustations was analyzed according endoscopic scoring of Lund and Kennedy [6], as follow:

- Grade 0: Absence of crustations.

- Grade 1: Mild crustations: partially filling the nasal cavity.

- Grade 2: Severe crustations: fully filling the nasal cavity.

Tissue healing was assessed also according to endoscopic scoring.

Lund and kennedy (6), as follow:

Good healing: Rapid mucosal re-epithelization, minimal crustations, no nasal synechiae, patient feel relief of nasal symptoms.

Moderate healing: Mucosal re-epithelization, mild to moderate crustations, with nasal synechiae, patient feel relief of nasal symptoms.

Poor healing: Delayed mucosal re-epithelization, severe crustations and nasal synechiae, persistent inflammations and infection and patient doesn't feel relief of his/her nasal symptoms.

In both groups follow up was carried-out on the first day, two weeks, one month and three months postoperatively to assess the previous parameters.

\section{Results}

The demographics of the trial groups did not show any significant difference as far as age and gender were concerned; in other words, age and gender distribution was practically the same in the assessed groups. Their ages ranged between 16 and 40 as shown in Table 1 . On the 1st day of post-op assessment, although both groups did not show significant difference as far as nasal bleeding and pain. 6 patients $(20 \%)$ of the group with partial turbinectomy presented with nasal bleeding that would require nasal packing and report pain that called for potent analgesia (opioid derivatives) (Table 2). On the 14th day of post-op assessment, the trial groups did not show significant differences as far as crust and nasal patency are concerned (Table 3). After one month, as regard healing, no 
Table 1. Demographics of the trial group.

\begin{tabular}{|c|c|c|c|}
\hline Age & \multicolumn{2}{|c|}{ with $(\mathrm{n}=30)$} & without $(\mathrm{n}=30)$ \\
\hline Mean \pm standard deviation & \multicolumn{2}{|c|}{$29.0 \pm 10$} & $28.9 \pm 7.9$ \\
\hline Male & 4 & 14.0 & 16.0 \\
\hline Female & 6 & 16.0 & 14.0 \\
\hline
\end{tabular}

Table 2. Day 1 post-op assessment of the trial groups.

\begin{tabular}{cccccc}
\hline Assessment & \multicolumn{2}{c}{ with $(\mathrm{n}=30)$} & \multicolumn{2}{c}{ without $(\mathrm{n}=30)$} & $\mathrm{p} \mathrm{value}^{(1)}$ \\
\hline & $\mathrm{N}^{\circ}$ & $\%$ & $\mathrm{~N}^{\circ}$ & $\%$ & \\
\hline Nasal Bleeding & & & & & 0.500 \\
None & 18 & 60.0 & 27 & 90.0 & \\
Mild & 06 & 20.0 & 02 & 07.0 & \\
Moderate & 06 & 20.0 & 1.0 & 03.0 & \\
Pain & & & & & 0.237 \\
None & - & - & 06 & 20.0 & \\
Mild & 24 & 80.0 & 21 & 70.0 & \\
Moderate & 06 & 20.0 & 03 & 10.0 & \\
\hline
\end{tabular}

Table 3. day $14^{\text {th }}$ postoperative assessment.

\begin{tabular}{|c|c|c|c|c|c|}
\hline \multirow[t]{2}{*}{ Assessment } & \multicolumn{2}{|c|}{ with $(\mathrm{n}=30)$} & \multicolumn{2}{|c|}{ without $(\mathrm{n}=30)$} & \multirow[t]{2}{*}{$\mathrm{p}$ value $\mathrm{e}^{(1)}$} \\
\hline & $\mathrm{N}^{\circ}$ & $\%$ & $\mathrm{~N}^{\circ}$ & $\%$ & \\
\hline Healing & & & & & 0.041 \\
\hline Good & 9 & 30.0 & 21 & 70.0 & \\
\hline Moderate & 15 & 50.0 & 09 & 30.0 & \\
\hline Poor & 06 & 20.0 & & & \\
\hline Crusts & & & & & $0.325(2)$ \\
\hline None & 15 & 50.0 & 21 & 70.0 & \\
\hline Moderate & 15 & 50.0 & 09 & 30.0 & \\
\hline Nasal patency & & & & & 0.171 \\
\hline Poor & - & - & 06 & 20.0 & \\
\hline Moderate & 09 & 30.0 & 15 & 50.0 & \\
\hline Good & 21 & 70.0 & 09 & 30.0 & \\
\hline
\end{tabular}

significant difference was seen. However, we must high-light the fact that the group without partial turbinectomy showed good healing $(80.0 \%)$ while the group with turbinectomy presented moderate healing $(60.0 \%)(\mathrm{p}=0.085)$. Regarding nasal patency, no significant difference was seen. However we must highlight the fact that the group with partial turbinectomy presented good nasal 
patency $(80.0 \%)$ while the non-turbinectomy group had moderate patency $(60.0 \%)(\mathrm{p}=0.062)($ Table 4$)$. On 3 months postoperative no significant difference was seen between both groups as regard healing and crusts. As regard nasal patency, there was a non significant deference between the trial groups. The group with partial turbinectomy presented good nasal patency $(80.0 \%)$ while the non-turbinectomy group had moderate patency (50.0\%) (Table 5).

\section{Discussion}

In the past, the electrocauterization of the inferior turbinate has been the most frequent procedure performed in order to reduce the volume of the inferior turbinate. Submucosal thermal ablation produces scarring, fibrosis and obliteration of the venous sinuses [7]. The classical concept statuses the fact that the electrocauterization will be effective if the inferior turbinate is capable of decongestion [8]. Partial turbinectomy is a removing the soft tissue from the lateral aspect of the inferior turbinate and the underlying bone, when bony hypertrophy is also involved [9] [10]. On the first post-operative day, reactionary hemorrhage was observed in 6 patients (20\%) who underwent PIT with SMD and one patients underwent SMD, this result is contrary to Vishnu et al. 2016 (3) who reported that the incidence of reactionary hemorrhage was (43.3\%) in PIT alone and in (10\%) patients who underwent SMD. In a study conducted by Imad et al. [5], in 2012 it was found that $40 \%$ of patients who underwent PIT had moderate bleeding while only $3 \%$ who underwent SMD had minimal bleeding. The studies done by Al-Baldawi [11] revealed that the incidence of reactionary hemorrhage was $12.5 \%$ in patients who underwent PIT, whereas none of the patients who underwent SMD had a reactionary hemorrhage. This indicate that prior SMD before PIT decreased incidence of reactionary hemorrhage. At post-operative day 1 about $80 \%$ of patients who underwent PIT with SMD had mild nasal pain and

Table 4. Day 30 post-op assessment of the trial groups.

\begin{tabular}{cccccc}
\hline Assessment & \multicolumn{2}{c}{ with $(\mathrm{n}=30)$} & \multicolumn{2}{c}{ without $(\mathrm{n}=30)$} & $\mathrm{p} \mathrm{value}^{(1)}$ \\
\hline & $\mathrm{N}^{\circ}$ & $\%$ & $\mathrm{~N}^{\circ}$ & $\%$ & 0.085 \\
Healing & 15 & 50.0 & 24 & 80.0 & \\
Good & 15 & 50.0 & 06 & 20.0 & 0.675 \\
Moderate & & & & & \\
Crusts & 09 & 30.0 & 21 & 70.0 & \\
None & 21 & 70.0 & 09 & 30.0 & $0.185(2)$ \\
Moderate & & & & & \\
Nasal Patency & - & - & 03 & 10.0 & \\
Poor & 09 & 30.0 & 18 & 60.0 & \\
Moderate & 21 & 70.0 & 09 & 30.0 & \\
Good & & & & & \\
\hline
\end{tabular}


Table 5. 3 months post-op assessment of the trial groups.

\begin{tabular}{cccccc}
\hline Assessment & \multicolumn{2}{c}{ with $(\mathrm{n}=30)$} & \multicolumn{2}{c}{ without $(\mathrm{n}=30)$} & p value $^{(1)}$ \\
\hline & $\mathrm{N}^{\circ}$ & $\%$ & $\mathrm{~N}^{\circ}$ & $\%$ & \\
\hline Healing & & & & & 0.763 \\
Good & 09 & 30.0 & 03 & 10.0 & \\
Moderate & & & & & 0.500 \\
Crusts & 21 & 70.0 & 24 & 80.0 & \\
None & 09 & 30.0 & 06 & 20.0 & \\
Moderate & & & & & $0.062(2)$ \\
Nasal patency & - & - & 06 & 20.0 & \\
Poor & 06 & 20.0 & 15 & 50.0 & \\
Moderate & 24 & 80.0 & 09 & 30.0 & \\
Good & & & &
\end{tabular}

$20 \%$ had moderate nasal pain. Patients who underwent SMD 10\% had no pain, at post-operative day 1 while $70 \%$ had mild pain and $20 \%$ had moderate pain. Vishnue et al. 2016 (3) reported that at post-operative day 1 about $36.7 \%$ of patients who underwent PIT had headache and nasal pain which was further reduced to $6.7 \%$ at the end of 1 week. The incidence of headache and nasal pain in patients who underwent SMD was $13.3 \%$ at post-operative day 1 and none of the patients had headache and nasal pain at the end of the first week. In a study conducted in Iraq by Al-Baldawi [11], the occurrence of nasal pain and headache was $12.5 \%$ in those who underwent PIT and only $5 \%$ of patients who underwent SMD had developed a headache. On the $14^{\text {th }}$ day of post-op assessment, the trial groups did not show significant differences as far as crust and nasal patency and this is concordant with Gommaa et al. [12]. At the end of the first month In Imad et al. [5], good nasal tissue healing was reported in $92 \%$ of SMD patients compared to $52 \%$ of PIT patients at the end of first postoperative month. In our study, $72 \%$ of SMD patients had good healing compared to $48 \%$ of PIT patients who had good nasal tissue healing, this difference may be attributed to the fact that when the inferior turbinate transected, this usually expose the edge of the inferior turbinate bone resulting in continuing crusting until the bone is re-covered with a mucosal surface [13]. After 30 days we found good nasal patancy in $70 \%$ and moderate patency in $30 \%$ of the patients who underwent submucosal electrocautery ablation coupled with PIT. On the other hand, in the patients who underwent only electrocautery ablation without PIT, we found good nasal patency in $30 \%$ and moderate patency in $60 \%$ and poor patency in $10 \%$. Such findings show that submucosal electrocautery ablation coupled with partial inferior turbinectomy is more efficient than electrocautery ablation alone. After 3 months we found good nasal patency in $80 \%$ of cases with PIT and 30\% in cases with electrocautery without PIT. This is in line with Fradi et al. [13] who reported good nasal patency in cases with PIT (96\%) than cases without PIT 
(66\%) On the other side Gommaa et al. [12] study results showed that subjective feeling of nasal obstruction was persisted for 2 weeks with no significant difference between the 2 groups. This non-significant difference was persisted for 3 months postoperatively and the nasal patency was equal in both groups (88\%).

\section{Conclusion}

From the comparative analysis of patients submitted to submucosal electrocautery ablation with and without partial inferior turbinectomy, after one day of follow-up, we concluded that although the incidence of reactionary hemorrhage in the group submitted to electrocautery with partial turbinectomy was higher than the second group, this incidence is much lower in cases submitted only to partial turbinectomy as reported by other studies. Cases of electrocautery with PIT have yielded better nasal patency when compared to submucosal electrocautery ablation alone.

\section{Acknowledgements}

To my colleges.

\section{Ethical Approval and Consent to Participate}

Approval from Aswan faculty of medicine ethics committee.

\section{Consent of Publication}

I agree for publication in journal of otolaryngology head \& neck surge.

\section{Author Contributions}

The corresponding author responsible for collection and analysis of data also about operative data and follow up of the patients. The second author responsible the tables and statistical analysis.

\section{Confidentiality}

The confidentiality of all participants admitted to this study will be protected to the fullest extend possible.

\section{Research Statement}

The purpose and nature of the study as will as risk had been explained to participants before admission to the study.

\section{Informed Consent}

The signed informed consent form will be a permanents part of the participant's study record.

\section{References}

[1] Steiner, W. and Werner, A.J. (2006) Lasers in Otorhinolaryngology, Head and Neck 
Surgery. Endo-Press, Tuttlingen.

[2] Hol, M.K. and Huizing, E.H. (2000) Treatment of Inferior Turbinate Pathology: Review and Critical Evaluation of the Different Techniques. Rhinology, 38, 157-166.

[3] Vishnu, M.S. and Rajamma, K.B. (2016) Comparison of Submucosal Diathermy and Partial Inferior Turbinectomy. International Journal of Scientific Study, 4, 120.

[4] Zapanta, P.E., De Vries, G.M. and Khoury, T. (2014) Turbinectomy. Medscape. http://emedicine.medscape.com/article/2051775-overview

[5] Imad, H., Javed and Sanaullah (2012) Comparison of Submucosal Diathermy with Partial Inferior Turbinectomy: A Fifty Case Study. J Postgrad Med Inst, 26, 91-95.

[6] Lund, V.J. and Kennedy, D.W. (1995) Quantification for Staging Sinusitis. The Staging and Therapy Group. Ann Otol Rhinol Laryngol Suppl, 167, 17-21.

[7] Codrut, M.S. (2015) Surgery for Nasal Obstruction in Inferior Turbinate Hypertrophy. Romanian Journal of Rhinology, 5, No. 17.

[8] Jones, A.S., Wight, R.G., Kabil, Y. and Buckingham, E. (1989) Predicting the Outcome of Submucosal Diathermy to the Inferior Turbinates. Clinical Otolaryngology, 14, 41-44. https://doi.org/10.1111/j.1365-2273.1989.tb00335.x

[9] Passali, D., Bellussi, L.M., Kern, E.B., Sarafoleanu, C. and Popescu, F.D. (2013) Rhinosinusal Inflammation and Infections: Modern Thinking and Current Treatment. Ed. Academiei Romane, Bucharest.

[10] Ozcan, K.M., Gedikli, Y., Ozcan, I., Pasaoglu, L. and Dere, H. (2008) Microdebrider for Reduction of Inferior Turbinate: Evaluation of Effectiveness by Computed Tomography. Journal of Otolaryngology_Head \& Neck Surgery, 37, 463-468.

[11] Al-Baldawi, M.H. (2009) Management of Inferior Turbinate Hypertrophy: A Comparaytive Study between Partial Inferior Turbinectomy and Submucosal Diathermy. Iraqi J Community Med, 22, 264-267.

[12] Gomaa, M.A., Nabi, O.G.A., Kerim, A.R.A.A. and Aly, A. (2015) Comparative Study between Partial Surgical Inferior Turbinectomy and Sub-Mucosal Diathermy of Inferior Turbinate for Treatment of Inferior Turbinate Hypertrophy. Otolaryngology, 5, 217. https://doi.org/10.4172/2161-119X.1000217

[13] Fradis, M., Malatskey, S., Magamsa, I. and Golz, A. (2002) Effect of Submucosal Diathermy in Chronic Nasal Obstruction Due to Turbinate Enlargement. American Journal of Otolaryngology, 23, 332-336. https://doi.org/10.1053/ajot.2002.126857

\section{Abbreviations}

SMD: Submucous cauterization

PIT: Partial inferior turbinectomy 